\title{
Meta-analysis of association between CT- based features and tumor spread through air spaces in lung adenocarcinoma
}

Qifan Yin ${ }^{1}$, Huien Wang ${ }^{1}$, Hongshang Cui ${ }^{1}$, Wenhao Wang ${ }^{1}$, Guang Yang ${ }^{1}$, Peng Qie ${ }^{1}$, Xuejiao Xun², Shaohui $\operatorname{Han}^{1}$ and Huining Liu ${ }^{1 *}$

\begin{abstract}
Objective: Spread through air space (STAS) is a novel invasive pattern of lung adenocarcinoma and is also a risk factor for recurrence and worse prognosis of lung adenocarcinoma after sublobar resection. The aims of this study are to evaluate the association between computed tomography (CT)-based features and STAS for preoperative prediction of STAS in lung adenocarcinoma, eventually, which could help us choose appropriate surgical type.

Methods: Systematic research was conducted to search for studies published before September 1, 2019. The association between $C T$-based features of radiological tumor size $>2 \mathrm{~cm}$, pure solid nodule, part-solid nodule or Percentage of solid component (PSC) $>50 \%$ and STAS was evaluated. According to rigorous inclusion and exclusion criteria. Eight studies including 2385 patients published between 2015 and 2018 were finally enrolled in our metaanalysis.

Results: Our results clearly depicted that there is no significant relationship between radiological tumor size $>2 \mathrm{~cm}$ and STAS with the combined OR of 1.47(95\% Cl:0.86-2.51). Meta-analysis of 3 studies showed that pure solid nodule in CT image were more likely to spread through air spaces with pooled OR of 3.10(95\%Cl2.17-4.43). Metaanalysis of 5 studies revealed the part-solid nodule in CT image may be more likely to appear STAS in adenocarcinoma (ADC) (combined OR:3.10,95\%Cl:2.17-4.43). PSC $>50 \%$ in CT image was a significant independent predictor in the diagnosis of STAS in ADC from our meta-analysis with combined OR of 2.95(95\%Cl:1.88-4.63).

Conclusion: In conclusion, The CT-based features of pure solid nodule、 part-solid nodule、PSC $>50 \%$ are promising imaging biomarkers for predicting STAS in ADC and may substantially influence the choice of surgical type. In future, more studies with well-designed and large-scale are needed to confirm the conclusion.
\end{abstract}

Keywords: Spread through air spaces, CT-based features, Lung adenocarcinoma, Association, Meta-analysis

\footnotetext{
*Correspondence: liuhuining1972@163.com

'Department of Thoracic Surgery, Hebei Provincal General Hospital, 348,

West He-Ping Road, Shijiazhuang 050051, Hebei Province, People's Republic of China

Full list of author information is available at the end of the article
}

(C) The Author(s). 2020 Open Access This article is licensed under a Creative Commons Attribution 4.0 International License, which permits use, sharing, adaptation, distribution and reproduction in any medium or format, as long as you give appropriate credit to the original author(s) and the source, provide a link to the Creative Commons licence, and indicate if changes were made. The images or other third party material in this article are included in the article's Creative Commons licence, unless indicated otherwise in a credit line to the material. If material is not included in the article's Creative Commons licence and your intended use is not permitted by statutory regulation or exceeds the permitted use, you will need to obtain permission directly from the copyright holder. To view a copy of this licence, visit http://creativecommons.org/licenses/by/4.0/ The Creative Commons Public Domain Dedication waiver (http://creativecommons.org/publicdomain/zero/1.0/) applies to the data made available in this article, unless otherwise stated in a credit line to the data. 


\section{Introduction}

With the wide use of low-dose helical computed tomography (LDCT) and high resolution computed tomography (HRCT) screening in lung cancer, the number of patients with early stage lung cancer characterized as pulmonary nodule has been found to be increasing before they become a unresectable lesion. However, lung cancer remains the first cancer-related death in both men and women [1]. Beyond infiltration of myofibroblast stroma and lymph vascular and pleural invasion, spread through air space (STAS) is regarded as a novel invasion pattern of lung adenocarcinoma, even though there are some controversies $[2,3]$. The conception of STAS was first introduced into our vision by Kadota and colleagues in 2015 [4]. In the 2015 World Health Organization (WHO) Classification [5], STAS was newly recognized as a pattern of tumor spread in lung adenocarcinoma. STAS is defined as micropapillary clusters, solid nests, or single cells spreading within air spaces beyond the edge of the main tumor [6]. STAS can be found in 14.8 to $56.4 \%$ of lung adenocarcinomas and has been proven to be a risk factor for survival and reoccurrence after operation [4, 7-10]. Comparing with STASnegative tumors, lung adenocarcinomas with STAS positive showed a significant worse recurrence-free survival and overall survival [10]. However, if surgical operation type was considered, sublobar resection of STAS-positive tumors has been reported to be associated with a high risk of distant and locoregional recurrence, while such association was not observed in patients undergoing lobectomy [4]. Therefore, preoperative knowledge of the presence of STAS may facilitate appropriate surgery type choosing.

As we all know, lobectomy and systematic lymph nodes dissection is the standard operation for the early stage lung cancer patients. In recent years, several studies indicated similar survival between sublobar resection and lobectomy for stage IA NSCLC [11-14], Compared with those who underwent traditional lobectomy. Patients who underwent sublobectomy had less lung tissue resected and more lung function preserved, The sublobar resection surgical approaches included wedge resection and segmentectomy. However, small adenocarcinoma with STASpositive should be treated by lobectomy combined with systematic dissection lymph nodes, not sublobar resection. If we can predict the STAS through the CT-based features before surgical resection, that would aid us in the selection of the optimum surgical procedure. The purpose of our meta-analysis is to evaluate the association between CT-based features and STAS and help us to predict STAS before surgery, eventually, which could help us choose appropriate surgical type.

\section{Methods}

\section{Literature search strategy}

We performed a systematic literature search through the following databases without date limitation: PubMed, Cochrane Library, Ovid and Web of Science databases. The search was updated to September 1, 2019. The main search terms included: "STAS" (e.g., "spread through air space", and "spread through air spaces",) and "lung cancer"[e.g., "lung neoplasm", "lung carcinoma","non-small cell lung cancer (NSCLC)", "small cell lung cancer (SCLC)"] and "CT-based features"(e.g.,"CT features", "Computed Tomography features", "CT manifestations", "CT characteristics"). The reference list was also checked for relevant articles.

\section{Inclusion and exclusion criteria}

The eligible studies were evaluated by two authors based on the inclusion criteria as follows: (1) studied patients with ADC were pathological examination confirmed; (2) STAS was confirmed by pathological examination; (3) studied patients underwent primary curative surgical resection; (4) correlation of STAS with CT features or CT manifestations was reported;(5) a single nodule. Articles didn't meet inclusion criteria would be excluded. Exclusion criteria were as follows: (1) abstracts, letters, case reports, reviews or nonclinical studies; (2) patients who underwent neoadjuvant chemotherapy and those with incomplete resection; (3) multiple nodules;(4) studies were not written in English; (5) patients were not lung adenocarcinoma.

\section{Data extraction and quality assessment}

The following data were extracted by two independent investigators; first author, publication year, nation, number of participants, participants characteristics (age, gender, the state of STAS, stage, CT-based features) and odd ratio (OR) and their corresponding 95\% confidence interval $(95 \% \mathrm{CI})$. Articles that could not be categorized based on title and abstract alone were retrieved for fulltext review. If disagreement occurred, two investigators discussed and reached consensus with a third investigator. Given all studies are retrospective observational studies, The Newcastle-Ottawa Scale (NOS) was used to assess each of the included studies quality by two independent authors. The NOS consists of three parts: selection (0-4points), comparability (0-2 points), and outcome assessment ( $0-3$ points). NOS scores of $\geq 6$ were regarded as high-quality studies.

\section{Statistical analysis}

We pooled OR corresponding 95\% CI to assess the association between CT-based features and STAS in lung ADC. The heterogeneity amid studies was tested by $\mathrm{I}^{2}$ statistic; If test results showed $\mathrm{I}^{2}$ value $>50 \%$, we 
considered high heterogeneity within studies and the random effect model was applied; If not $\left(\mathrm{I}^{2}\right.$ value $\left.\leq 50 \%\right)$, the fixed effect model was used. Additionally, if there is considerable heterogeneity, meta regression analysis with restricted maximum likelihood (REML) method and subgroup analysis will be conducted. Funnel plot and Egger's test were used to estimate publication bias. To evaluate the stability of the results, we conducted sensitivity analysis to test it. These statistic data was performed using STATA version 12.0. A $p<0.05$ was considered statistically significant differences.

\section{Results}

\section{Search results}

A total of 206 articles were searched:120 from Pubmed, 24 from Ovid,20 from Cochrane Library and 42 from Web of science. After carefully inspection of these articles, 8 studies including 2385 patients published between 2015 and 2018 were finally enrolled in our metaanalysis. The detail processes of study selection were showed in the flow diagram (Fig. 1). Among them, five studies were from Japan, one study was performed in USA, China and Republic of Korea, respectively. OR and $95 \%$ CI were extracted directly or calculated indirectly in 8 studies. In our meta analysis, not every association has been evaluated using every paper included in the metaanalysis; four studies revealed the association between radiological tumor size $>2 \mathrm{~cm}$ and STAS, three studies illuminated the relation between pure solid nodule and STAS, five studies depicted the connection between part-solid nodule and STAS, two studies demonstrated the association between percentage of solid component (PSC) $>50 \%$ and STAS. The PSC was calculated as follows: [maximum diameter of the solid component/ maximum diameter of the lesion] $\times 100$, where the maximum diameter of the lesion includes both ground-glass opacity and solid component in CT image. The characteristics of the enrolled studies were shown in Table 1.

\section{The association between radiological tumor size $>2 \mathrm{~cm}$ and STAS in ADC}

The results of the association are showed in Fig. 2. Four studies presented the data to evaluated the association between radiological tumor size $>2 \mathrm{~cm}$ and STAS in our meta-analysis. Considering the heterogeneity $\left(\mathrm{I}^{2}=62.8 \%\right.$, $P=0.045)$. Therefore, a random-effect model was applied. Our results clearly depicted that there was no significant relationship between radiological tumor size $>2 \mathrm{~cm}$ and STAS with the combined OR of $1.47(95 \%$ CI:0.86-2.51; Fig. 2). The CT-based feature of radiologic

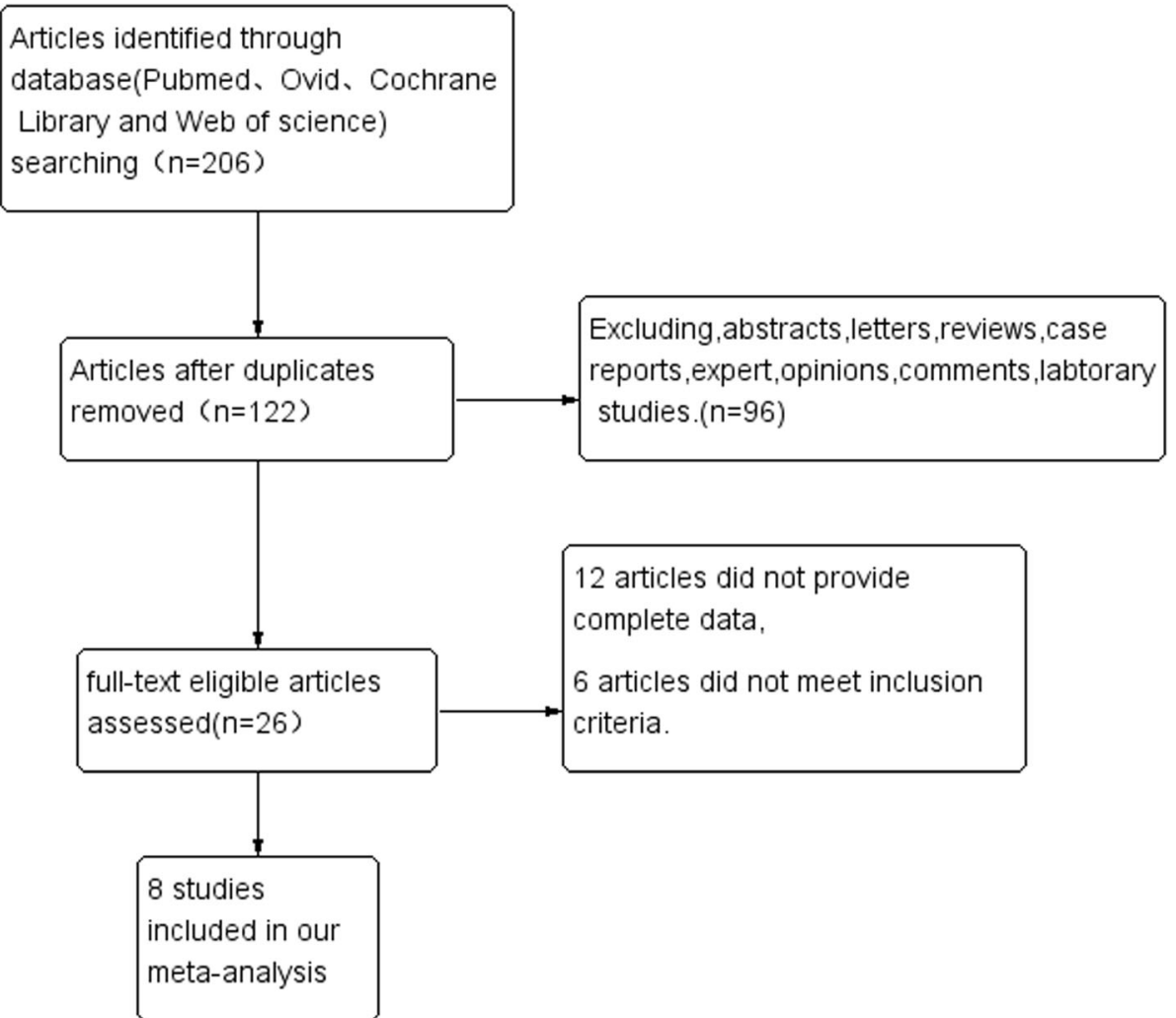

Fig. 1 The flow diagram for retrieving eligible articles 
Table 1 The basic characteristics of enrolled studies

\begin{tabular}{|c|c|c|c|c|c|c|c|c|c|c|}
\hline author & year & region & $N(M / F)$ & year & STAS(+/-) & subtype & stage & $\begin{array}{l}\text { Lobectomy/ } \\
\text { sublobar } \\
\text { Resection }\end{array}$ & NOS & CT-based features \\
\hline Kadota et al. [4] & 2015 & Japan & $411(164 / 247)$ & 68 & $155 / 256$ & $\mathrm{ADC}$ & । & $291 / 120$ & 7 & part-solid nodule. \\
\hline Shiono et al. [15] & 2016 & Japan & $318(149 / 169)$ & 70 & $47 / 271$ & $\mathrm{ADC}$ & । & $202 / 116$ & 5 & pure solid nodule. \\
\hline Dai et al. [10] & 2017 & China & $383(178 / 205)$ & 60 & $116 / 267$ & $\mathrm{ADC}$ & । & $364 / 19$ & 6 & $\begin{array}{l}\text { radiological tumor } \\
\text { size }>2 \mathrm{~cm} \text {. }\end{array}$ \\
\hline Masai et al. [16] & 2017 & Japan & $508(248 / 260)$ & 66 & $76 / 432$ & $A D C$ & । & $0 / 508$ & 7 & part-solid nodule. \\
\hline Toyokawa et al. [17] & 2018 & Japan & $327(153 / 174)$ & 69 & 191/136 & $A D C$ & I-IV & $235 / 84$ & 7 & $\begin{array}{l}\text { radiological tumor } \\
\text { size }>2 \mathrm{~cm} \text {,pure solid } \\
\text { nodule,part-solid nodule. }\end{array}$ \\
\hline $\begin{array}{l}\text { de Margerie-Mellon } \\
\text { et al. [18] }\end{array}$ & 2018 & USA & $80(27 / 53)$ & 68 & $40 / 40$ & $A D C$ & NA & NA & 6 & $\begin{array}{l}\text { radiological tumor } \\
\text { size }>2 \mathrm{~cm} \text {, part-solid } \\
\text { nodule. }\end{array}$ \\
\hline Kim et al. [19] & 2018 & $\begin{array}{l}\text { Republic of } \\
\text { Korea }\end{array}$ & $276(129 / 147)$ & 59 & $92 / 184$ & $A D C$ & $|-|||$ & $226 / 50$ & 6 & $\begin{array}{l}\text { pure solid nodule, } \\
\text { part-solid nodule. }\end{array}$ \\
\hline Toyokawa et al. [20] & 2018 & Japan & $82(40 / 42)$ & 71 & $31 / 51$ & $\mathrm{ADC}$ & । & $0 / 82$ & 7 & $\begin{array}{l}\text { radiological tumor } \\
\text { size }>2.0 \mathrm{~cm}\end{array}$ \\
\hline
\end{tabular}

tumor size larger than $2 \mathrm{~cm}$ cannot be used as a biomarker to predict STAS. This finding shows that tumors larger than $2 \mathrm{~cm}$ in CT image are not necessarily more likely to spread through air spaces in ADC.

\section{The association between pure solid nodule and STAS in} ADC

In our mate-analysis, Three included studies evaluating the relationship between pure solid nodule in CT image and STAS were analyzed. Since there is no heterogeneity $\left(\mathrm{I}^{2}=0.0 \%, P=0.858\right)$,Fixed-effect model was applied.
Our result revealed a strong association between pure solid nodule and STAS in ADC with pooled OR of 3.10(95\%CI2.17-4.43, Fig. 3). Therefore, combined effect provided the evidence that pure solid nodule in CT image were more likely to spread through air spaces, which might be a marker to predict STAS in ADC.

\section{The association between part-solid nodule and STAS in ADC}

For the relationship between part-solid nodule in CT image and STAS in ADC. The five studies enrolled into

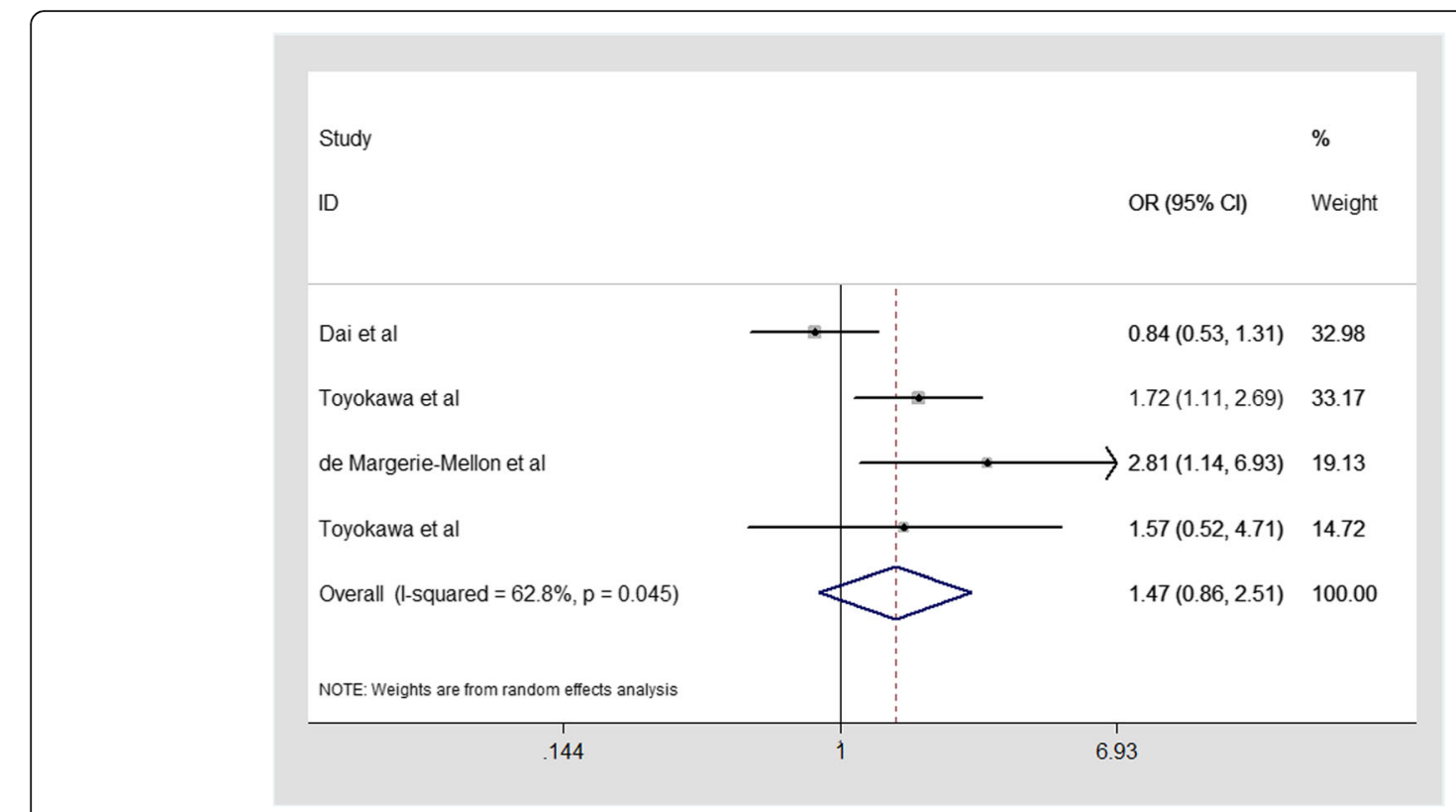

Fig. 2 Meta-analysis of the association between radiological tumor size $>2 \mathrm{~cm}$ and STAS in ADC 


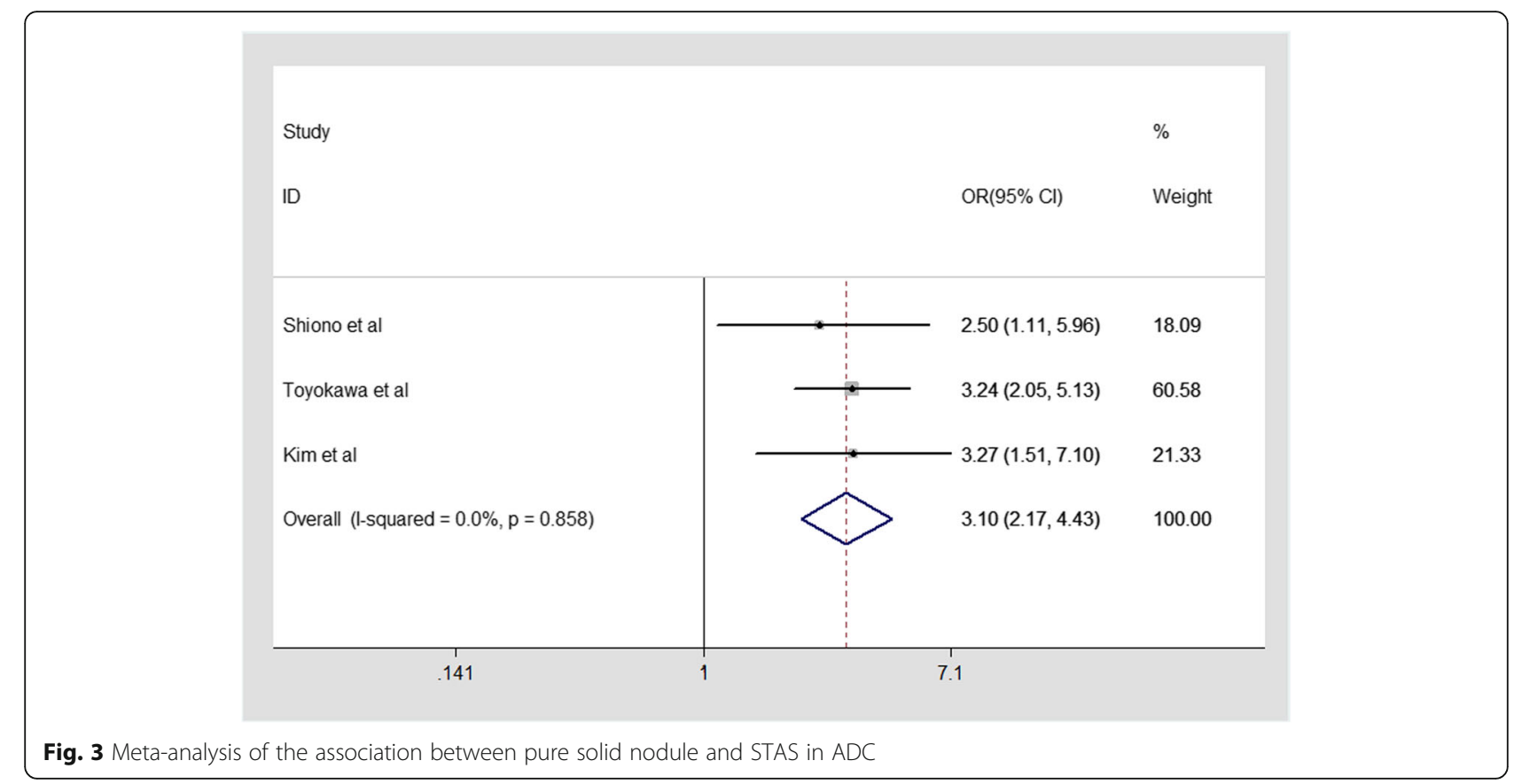

our mate-analysis were analyzed by random effect model because of larger heterogeneity $\left(\mathrm{I}^{2}=72.3 \%, p=\right.$ 0.006 , Fig. 4). From our mate-analysis, our result clearly showed that there was a significant association between part-solid nodule and STAS in ADC. Therefore, The part-solid nodule in CT scan may be more likely to appear STAS in ADC (combined OR:3.10, 95\%CI:2.17-4.43, Fig. 4).
The association between percentage of solid component(PSC) $>50 \%$ and STAS in ADC

Percentage of the solid component (PSC) was defined as the ratio of maximum diameter of the solid component to the tumor average diameter multiplied by $100 \%$ in CT image. Two studies presented data to evaluated the association between PSC $>50 \%$ and STAS in our mateanalysis. Fixed effect model was applied because of little

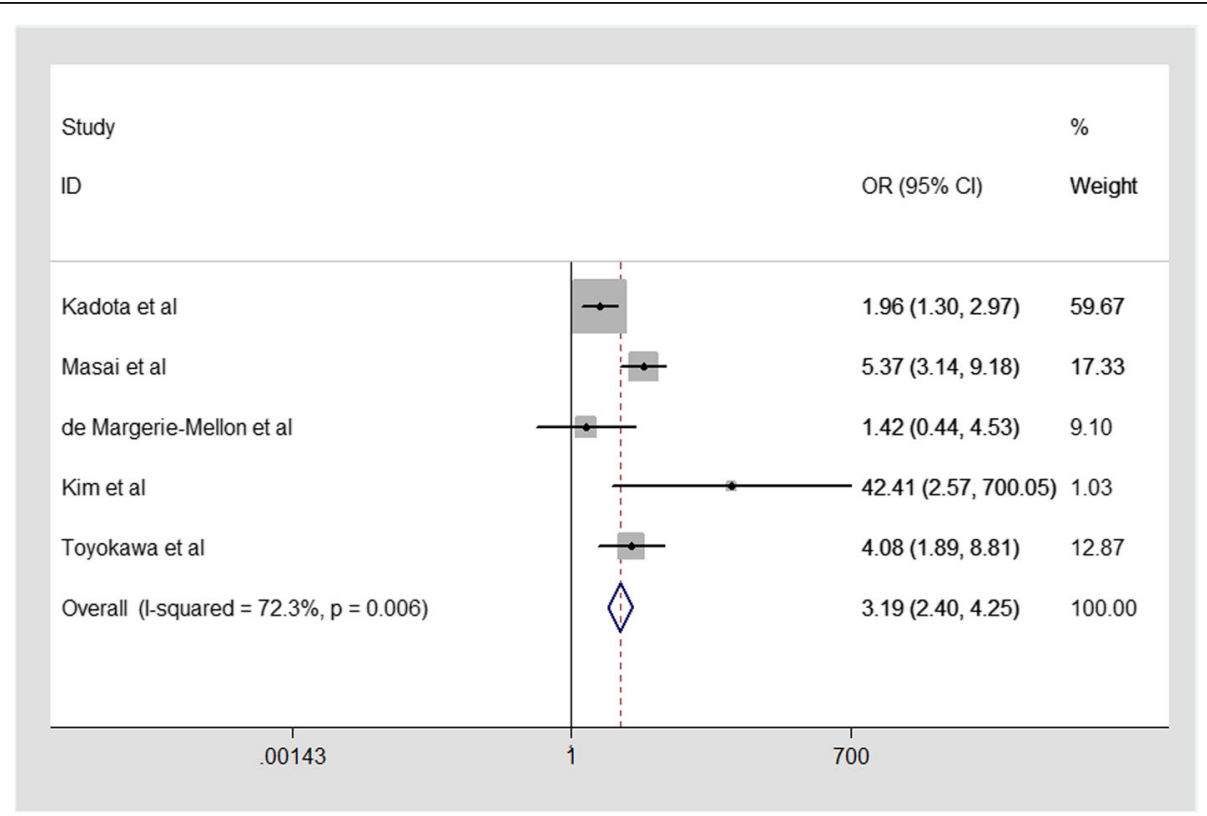

Fig. 4 Meta-analysis of the association between part solid nodule and STAS in ADC 
heterogeneity $\left(\mathrm{I}^{2}=42.6 \%, p=0.187\right.$, Fig. 5$)$. PSC $>50 \%$ was a significant independent predictor in the diagnosis of STAS in ADC from our result with combined OR of 2.95(95\%CI:1.88-4.63, Fig. 5). de Margerie-Mellon et al. [18] reported that high proportion of solid component diameter to tumor average diameter as CT manifestation in pulmonary adenocarcinomas was presented as a predictive biomarker in the diagnosis of STAS. From our mate-analysis, the tumor with PSC $>50 \%$ is more likely to spread through air spaces in ADC.

\section{Sensitivity analysis and publication bias}

The outcomes were similar whether fixed-effects models or random-effects models were used. Publication bias was evaluated by Begg's funnel plot and Egger's linear regression test, Egger's test $(p>0.05)$ showed that there was no significant publication bias of studies included this meta-analysis. The shapes of the funnel plot are symmetric visually (Fig. 6) and no proof of publication bias was obtained.

\section{Discussions}

To our knowledge. In recent years, there have been several studies exploring the relationship between preoperative CT findings and STAS of lung adenocarcinomas [17-19, 21]. de Margerie-Mellon and colleagues noticed that the size and rate of solid components were associated with STAS [18]. Kim et al. found that the percentage of solid component was an independent predictor of STAS [19]. Our primary result from this mateanalysis showed the CT-based features of pure solid nodule、 part-solid nodule、 $\mathrm{PSC}>50 \%$ have the potential to be a promising imaging biomarkers to preoperatively predict STAS, which could facilitate surgeons' operation selection.

STAS is a recently described novel invasive pattern of lung cancer. Several studies showed that STAS was associated with recurrence and a decrease in overall survival in those patients with early-stage lung adenocarcinomas who received limited resection $[4,7,10,22]$. However, if patients with STAS positive tumors had their entire lung lobe removed early, there was no significant association between STAS and tumor recurrence and overall patient survival [4]. Therefore, it is desirable for surgeons to choose the optimal operative type according to STAS status.

From our results, The CT characteristics of pure solid nodule、 part-solid nodule、 PSC $>50 \%$ are promising imaging biomarkers for predicting STAS in ADC from our mate-analysis. STAS was more likely to manifest as pure solid nodule , part-solid nodule or PSC $>50 \%$ in thin section CT image. de Margerie-Mellon et al. [18] reported that the nodules with maximum diameter of solid component $\geq 1 \mathrm{~cm}$ were more likely to appear STAS with OR of 5.303(95\%CI:1.85-15.23). Our conclusion is also consistent with current management guidelines and treatment strategies for resectable lung cancer. The National Comprehensive Cancer Network guidelines for nonsmall cell lung cancer suggest that sublobar resection is appropriate for small $(\leq 2 \mathrm{~cm})$ peripheral nodules with $50 \%$ or greater ground-glass appearance at CT [23]. In our study, the nodules with pure solid nodule、 partsolid nodule or PSC $>50 \%$, which are more likely to spread through air spaces, are more suitable to choose

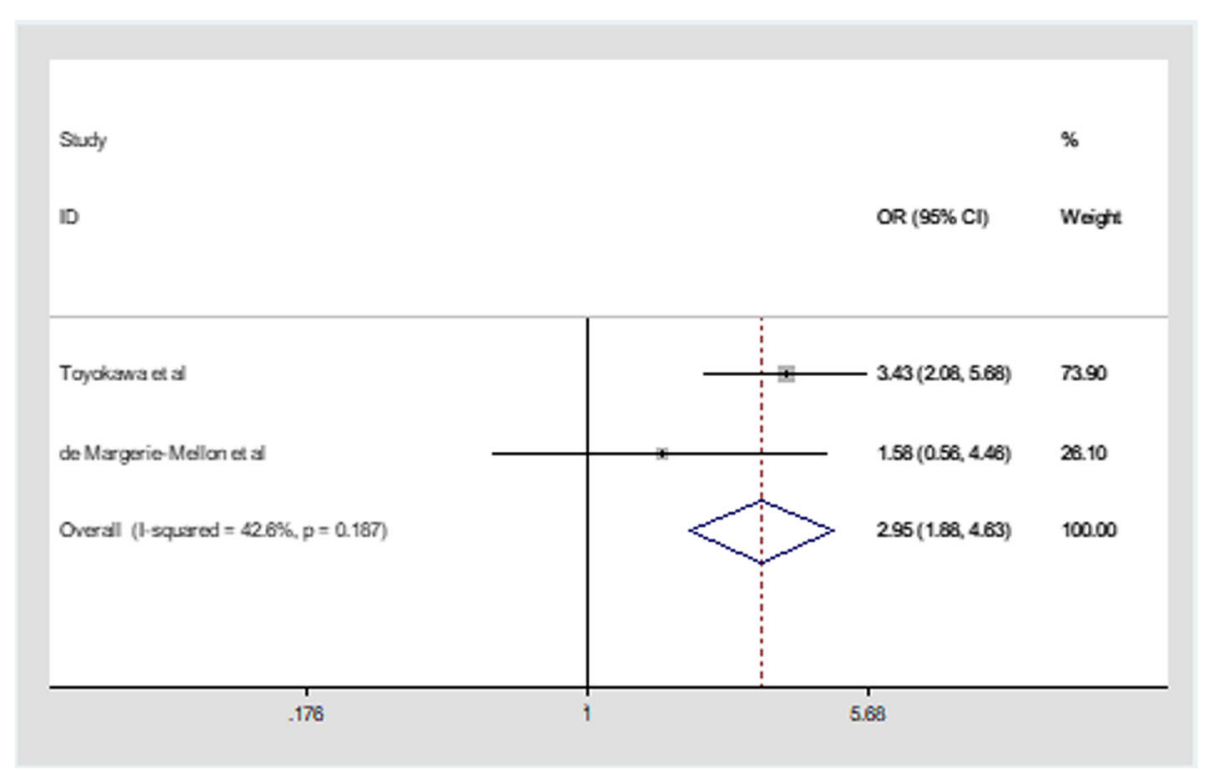

Fig. 5 Meta-analysis of the association between PSC $>50 \%$ and STAS in ADC 


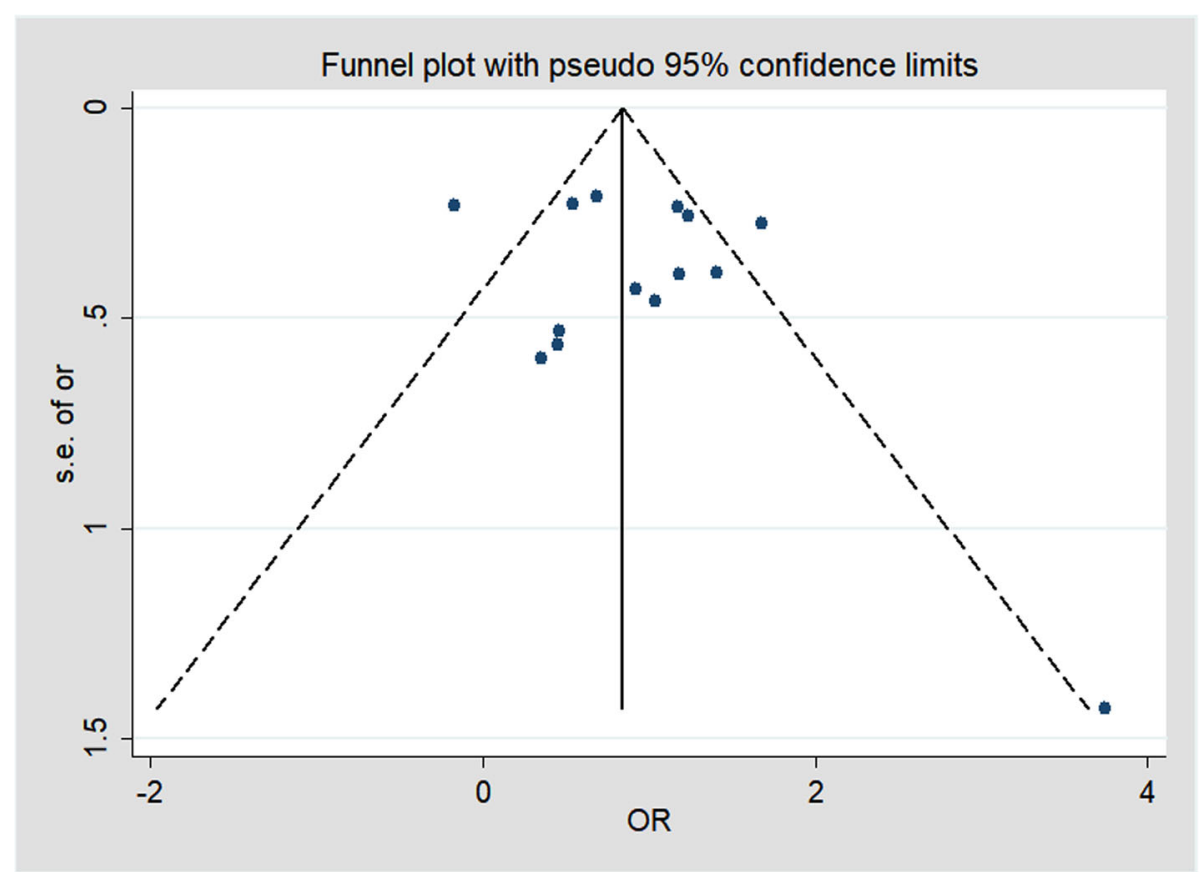

Fig. 6 The funnel plot

standard lobectomy than sublobar resection in ADC. Toyokawa et al. [17] demonstrated that STAS-positive adenocarcinomas were significantly associated with a radiological tumor diameter larger than $2.0 \mathrm{~cm}(\mathrm{OR}=$ $1.72,95 \mathrm{CI} \%(1.11-2.70) ; P=0.02)$. But our mate-analysis didn't reach a same conclusion at this point. In our opinion, the majority of GGO with tumor diameter larger than $2.0 \mathrm{~cm}$ are unlikely to appear STAS in ADC. The other CT features, such as vascular convergence sign, vacuole sign, pleural indentation, spiculation, air bronchogram, haven't been enrolled into our metaanalysis, because so little study has been done about them. Hopefully, more and more research will be done to evaluate the association between the other CT features and STAS in the future.

There are several limitations in our meta-analysis. First, the enrolled studies were retrospective, which contributed to that some bias were inevitable. Second, our meta-analysis only enrolled studies published in English language so as to some relevant studies in other languages were omitted, which might lead to publication bias and the limitation of applicable populations. Third, the number of enrolled studies is too low, in future, more studies with well-designed and large-scale are needed to confirm the conclusion. Fourth, our metaanalysis just provided evidence of association between CT-based features and STAS in ADC patients, but that doesn't mean a causal relationship between them, cautious interpretation of the result is vital and more precise prospective studies is desperately needed.

\section{Conclusions}

In conclusion, The CT-based features of pure solid nodule、part-solid nodule、 PSC $>50 \%$ are promising imaging biomarkers for predicting STAS in ADC and may substantially influence the choice of surgical type. In future, more studies with well-designed and large-scale are needed to confirm the conclusion.

\section{Abbreviations}

STAS: Spread through air spaces; GGO: Ground glass opacity; ADC: Adenocarcinoma; OR: Odd ratio; Cl: Confidence interval; PSC: Percentage of solid component; NSCLC: Non-small cell lung cancer; HRCT: High resolution computed tomography; LDCT: Low-dose helical computed tomography

\section{Acknowledgments}

I would like to thank my instructor, professor Liu,for his guidance of this research and my colleagues for their strong support of this study. No funding was involved in this study.

\section{Authors' contributions}

Huining Liu and Qifan Yin conceived the study. Huien Wang, Guang Yang collected the data, Peng Qie, Shaohui Han analysed the data and performed statistical analyses. Hongshang Cui,Wenhao Wang searched researches. Qifan Yin and Xeujiao Xun drafted the manuscript. Huining Liu gave important intellectual contribution and critically revised the manuscript. All authors read and approved the final manuscript.

Funding

No funding was involved in this study.

\section{Availability of data and materials}

The datasets used and analysed during the current study are available from the corresponding author on reasonable request. 


\section{Ethics approval and consent to participate}

This study conforms to the ethical guidelines in a priori approval by the local Ethical Committee of the Hebei General Hospital. This study was approved by our institutional review board (IRB number 20191205).

\section{Consent for publication}

Not applicable.

\section{Competing interests}

The authors declare that they have no competing interests.

\section{Author details}

'Department of Thoracic Surgery, Hebei Provincal General Hospital, 348, West He-Ping Road, Shijiazhuang 050051, Hebei Province, People's Republic of China. ${ }^{2}$ Department of Pharmacy, Hebei Provincal General Hospital, 348, West He-Ping Road, Shijiazhuang 050051, Hebei Province, People's Republic of China.

Received: 28 April 2020 Accepted: 1 September 2020

Published online: 10 September 2020

\section{References}

1. Siegel RL, Miller KD, Jemal A. Cancer statistics, 2019. CA Cancer J Clin. 2019; 69:7-34.

2. Amin MB, Tamboli $\mathrm{P}$, Merchant $\mathrm{SH}$, et al. Micropapillary component in lung adenocarcinoma: a distinctive histologic feature with possible progn ostic significance. Am J Surg Pathol. 2002;26:358-64.

3. Blaauwgeers $H$, Flieder $D$, Warth $A$, et al. A prospective study of loose tissue fragments in non-small cell lung Cancer resection specimens: an a Iternative view to "spread through air spaces". Am J Surg Pathol. 2017;41:1226-30.

4. Kadota K, Nitadori J, Sima CS, et al. Tumor spread through air spaces is an important pattern of invasion and impacts the frequency and Loc ation of recurrences after limited resection for small stage I lung adenocarcinomas. J Thorac Oncol. 2015;10:806-14.

5. Travis WD, Brambilla E, Nicholson AG, et al. The 2015 World Health Organization classification of lung tumors: impact of genetic, clinical and radiologic advances since the 2004 classification. J Thorac Oncol. 2015;10: 1243-60.

6. Warth A. Spread through air spaces (STAS): a comprehensive update. Transl Lung Cancer Res. 2017;6:501-7.

7. Shiono S, Endo M, Suzuki K, et al. Spread through air spaces is a prognostic factor in sublobar resection of non-small cell lung Cancer. Ann Thorac Surg. 2018;106:354-60.

8. Liu H, Yin Q, Yang G, Qie P. Prognostic impact of tumor spread through air spaces in non-small cell lung cancers: a Meta-analysis including 3564 patients. Pathol Oncol Res. 2019.25(4):1303-10.

9. David EA, Atay SM, McFadden PM, Kim AW. Sublobar or suboptimal: does tumor spread through air spaces signify the end of sublobar resections $f$ or T1N0 adenocarcinomas? J Thorac Oncol. 2019;14:11-2.

10. Dai $\mathrm{C}$, Xie H, Su H, et al. Tumor spread through air spaces affects the recurrence and overall survival in patients with lung?Ade nocarcinoma $>2$ to $3 \mathrm{~cm}$. J Thorac Oncol. 2017;12:1052-60.

11. Sugi K, Kobayashi S, Sudou M, et al. Long-term prognosis of videoassisted limited surgery for early lung cancer. Eur J Cardiothorac Surg. 2010;37:456-60

12. Wisnivesky JP, Henschke Cl, Swanson S, et al. Limited resection for the treatment of patients with stage IA lung cancer. Ann Surg. 2010;251:550-4.

13. Zhong C, Fang W, Mao T, et al. Comparison of thoracoscopic segmentectomy and thoracoscopic lobectomy for small-sized stage IA lung c ancer. Ann Thorac Surg. 2012;94:362-7.

14. Tsutani $Y$, Miyata $Y$, Nakayama $H$, et al. Oncologic outcomes of segmentectomy compared with lobectomy for clinical stage IA lung adenocarcinoma : propensity score-matched analysis in a multicenter study. J Thorac Cardiovasc Surg. 2013;146:358-64.

15. Shiono S, Yanagawa N. Spread through air spaces is a predictive factor of recurrence and a prognostic factor in stage I lun g adenocarcinoma. Interact Cardiovasc Thorac Surg. 2016;23:567-72

16. Masai $K$, Sakurai H, Sukeda A, et al. Prognostic impact of margin distance and tumor spread through air spaces in limited resection for Pri mary lung Cancer. J Thorac Oncol. 2017;12:1788-97.
17. Toyokawa G, Yamada Y, Tagawa T, et al. Computed tomography features of resected lung adenocarcinomas with spread through air spaces. J Thorac Cardiovasc Surg. 2018;156:1670-1676.e1674.

18. de Margerie-Mellon C, Onken A, Heidinger BH, et al. CT manifestations of tumor spread through airspaces in pulmonary adenocarcinomas presenting as subsol id nodules. J Thorac Imaging. 2018;33:402-8.

19. Kim SK, Kim TJ, Chung MJ, et al. Lung adenocarcinoma: CT features associated with spread through air spaces. Radiology. 2018;289:831-40.

20. Toyokawa G, Yamada Y, Tagawa T, Oda Y. Significance of spread through air spaces in early-stage lung adenocarcinomas undergoing limited rese ction. Thorac Cancer. 2018;9:1255-61.

21. de Margerie-Mellon C, VanderLaan PA, Bankier AA. CT manifestations of tumor spread through air spaces in lung adenocarcinoma: different pathways towar d common perspectives. Radiology. 2019;290:271-2.

22. Onozato $M L$, Kovach $A E$, Yeap BY, et al. Tumor islands in resected earlystage lung adenocarcinomas are associated with unique clinicopatholog ic and molecular characteristics and worse prognosis. Am J Surg Pathol. 2013; 37:287-94.

23. Denlinger CS, Sanft T, Baker KS, et al. Survivorship, version 2.2018, NCCN clinical practice guidelines in oncology. J Natl Compr Cancer Netw. 2018;16: 1216-47.

\section{Publisher's Note}

Springer Nature remains neutral with regard to jurisdictional claims in published maps and institutional affiliations.
Ready to submit your research? Choose BMC and benefit from:

- fast, convenient online submission

- thorough peer review by experienced researchers in your field

- rapid publication on acceptance

- support for research data, including large and complex data types

- gold Open Access which fosters wider collaboration and increased citations

- maximum visibility for your research: over $100 \mathrm{M}$ website views per year

At $\mathrm{BMC}$, research is always in progress.

Learn more biomedcentral.com/submissions 